\title{
AMPUTATION OF ALL TOES
}

\section{A Review of Forty-seven Amputations}

\author{
Michael Flint and Rodney Sweetnam. London, England
}

From the Institute of Orthopaedics, Royal National Orthopaedic Hospital, London and Stanmorc

And she said-." It's a fact the whole world knows,

" That Pobbles are happier without their toes."

-EDWARD Lear (Nonsense Rhymes)

Fixed clawing of the toes with dorsal dislocation of the metatarso-phalangeal joints is often seen in patients with rheumatoid arthritis, pes cavus, and severe hallux valgus. It may cause much pain and restriction of activity. Some patients can be made comfortable by regular chiropody and the provision of special shoes, but often conservative measures are only partly successful, and a more radical approach to the problem is necessary.

Moderate fixed deformity of the toes can, of course. be corrected by arthrodesis of the interphalangeal joints or by one of the many operations that shorten the skeletal framework

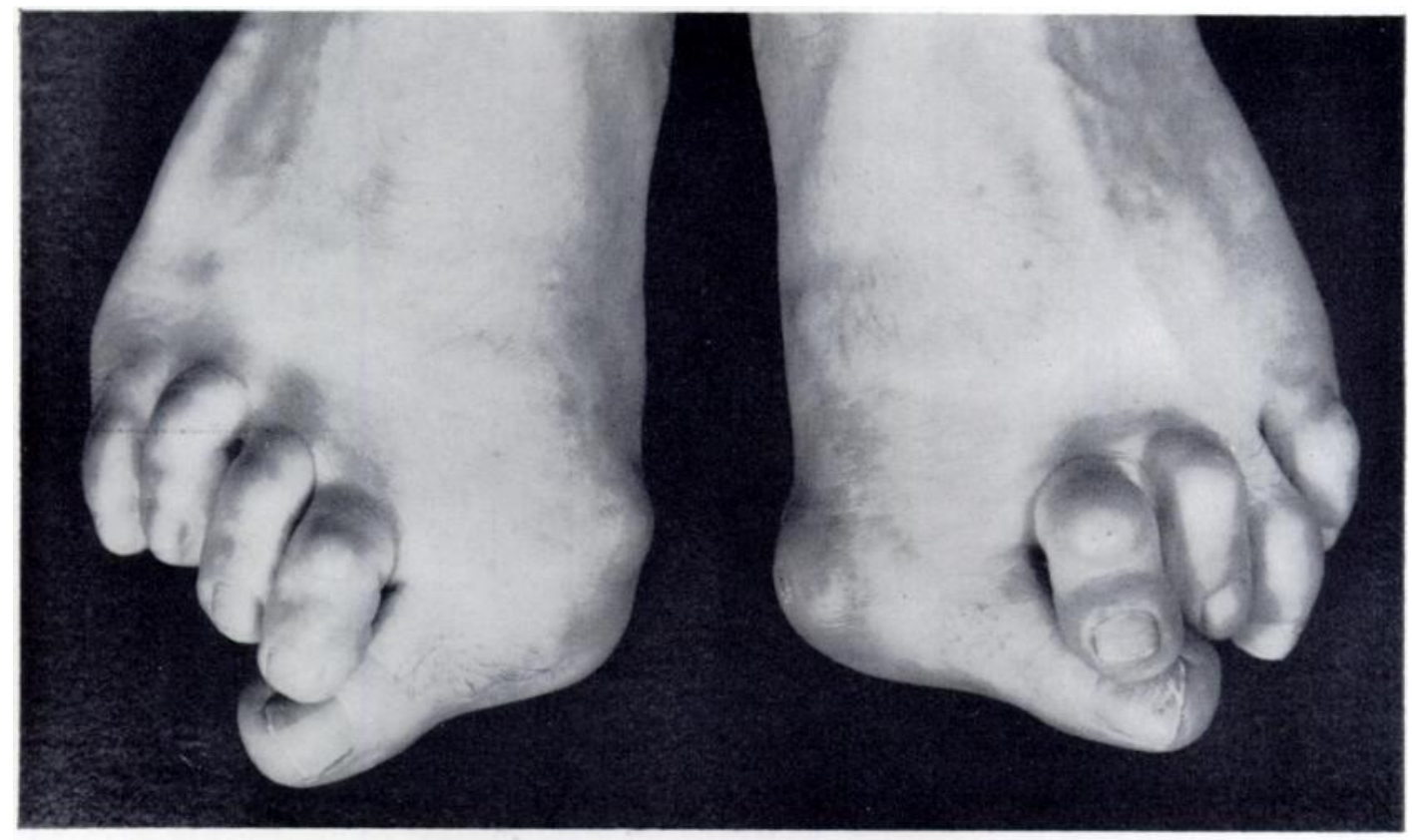

Fig. 1

Fixed toe deformity with multiple metatarso-phalangeal dislocations.

of the toe; but in the severely crippled foot with multiple metatarso-phalangeal dislocations and fixed deformities of the toes these minor procedures are often ineffective or disappointing.

Hoffmann (1912) introduced an operation to correct multiple toe deformitics by excision of all the metatarsal heads through a single transverse plantar incision. He considered that the operation removed the force tending to displace the toes dorsally and so relieved pain and corrected deformity. Fowler $(1957,1959)$ described an operation using a dorsal approach. 
He advised removal of the bases of the proximal phalanges, refashioning of the metatarsal heads and excision of the painful callus under the prominent metatarsal heads.

Many surgeons, however, believe that there is no value in preserving stiff deformed functionless toes, and advise their amputation in severe cases (Nissen 1953. Pridic 1959. Sayle-Creer 1959).

Hendry (1959) has performed this amputation several hundred times with excellent results. and credit should be given to him for being among the first to draw attention to its merits. At

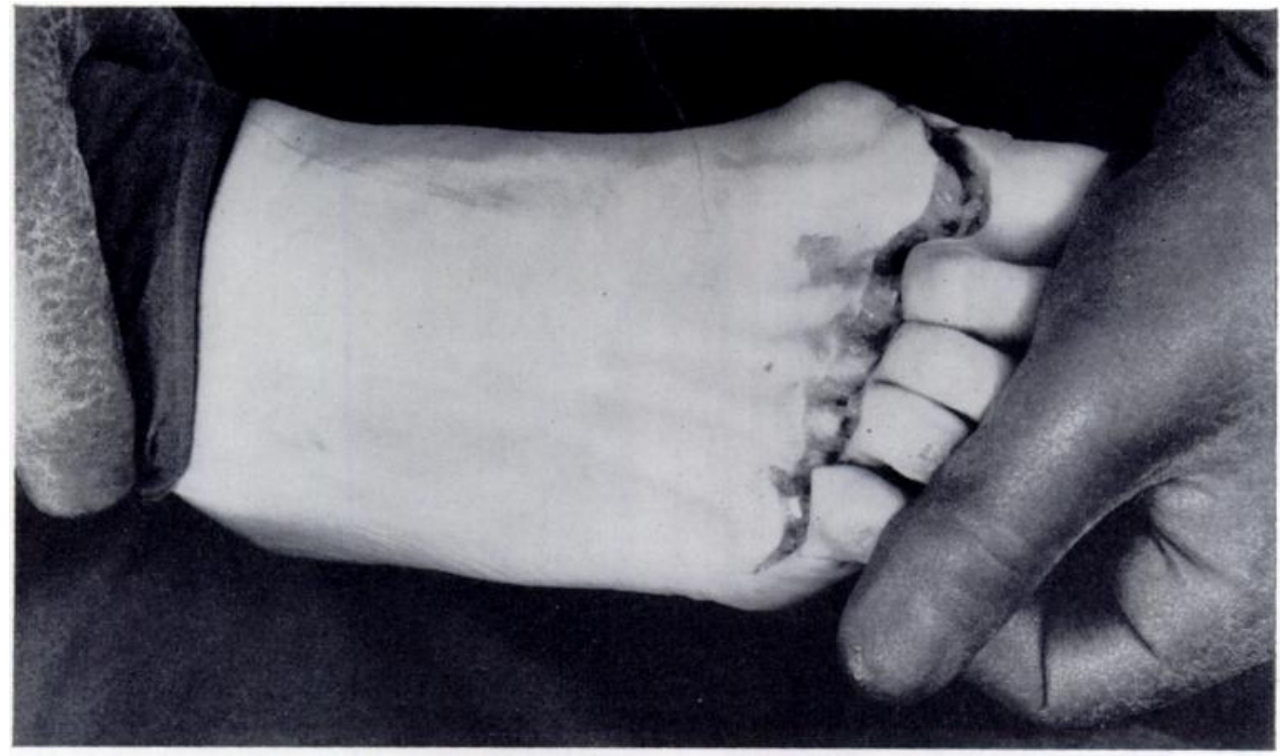

Fig. 2

Dorsal incision crossing proximal phalanges.

the Birmingham meeting of the British Orthopaedic Association in 1938 he showed a small series of patients, all of whom were delighted with the relief of pain after amputation of all their toes. Although amputation of all the toes of a foot must be a widespread practice, we have been unable to find any other reference to a series of cases so treated. Certainly the operation was wcll known to the first generation of orthopaedic surgeons in this country. We have learned from several sources that Sir Robert Jones frequently did the operation. and a patient upon whom he had operated many years before was shown at the Exeter meeting of the Royal Society of Medicine in 1937 by Mr Norman Capener. Catterall and Oakley (1957) found a similar operation of great value in the treatment of gangrenous or infected toes in the diabetic ischaemic foot.

Recently we have had the opportunity of reviewing forty-seven amputations in twentyeight patients. Most were operated upon more than five years ago and the good results seem worth recording.

\section{TECHNIQUE OF OPERATION}

In this series the technique used was that described by Nissen (1957). The incision begins over the first metatarsal head and runs transversely across the dorsum of the toes to the lateral border of the foot (Fig. 2). After crossing the proximal phalanx of each toe. it dips down into the intervening web spaces. and in this way adequate skin flaps are assured. A similar incision is made on the plantar aspect (Fig. 3 ) and both are deepened to bone through which the extensor and flexor tendons and neurovascular bundles are divided, and each toe is disarticulated in turn. When all

VOL. 42 B, NO. 1, FEBRUARY 1960 


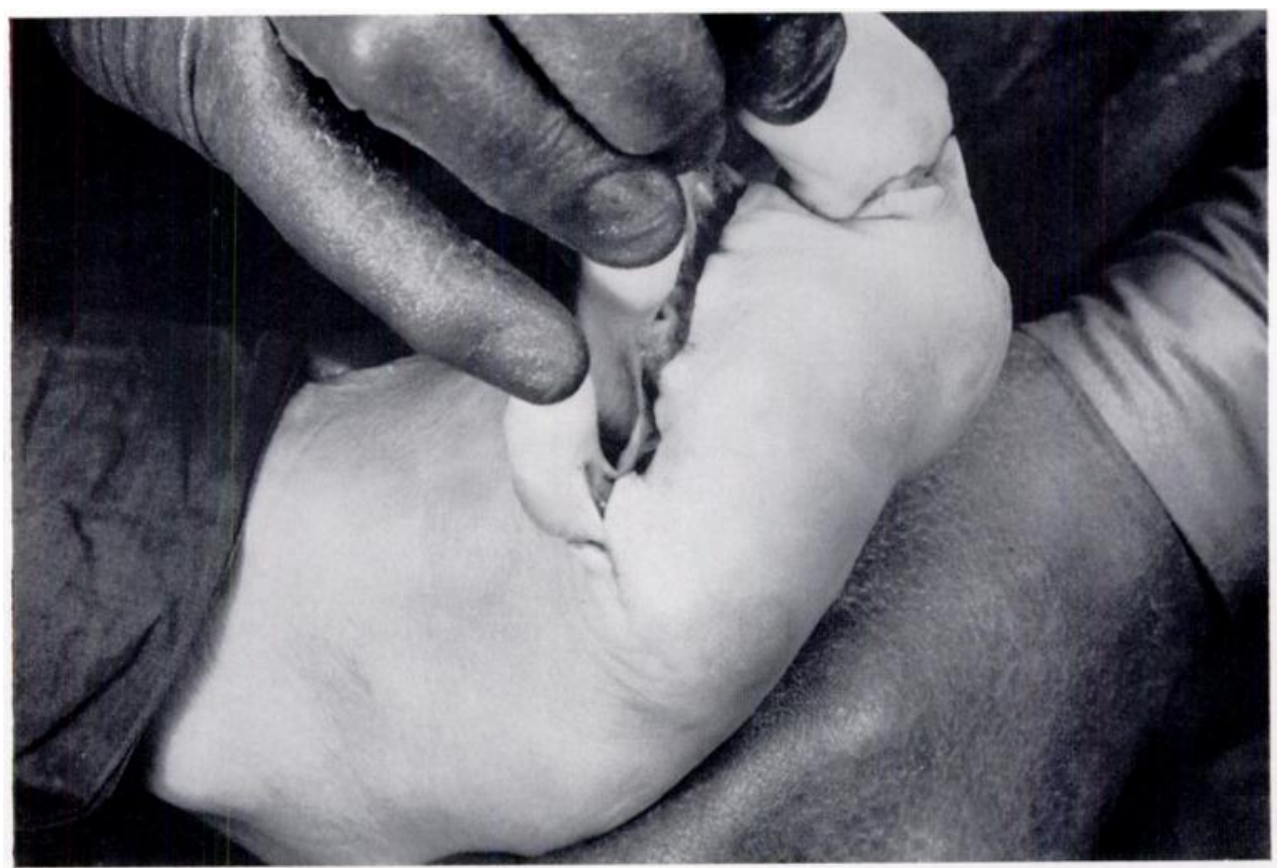

FIG. 3

Plantar incision across proximal phalanges and webs.

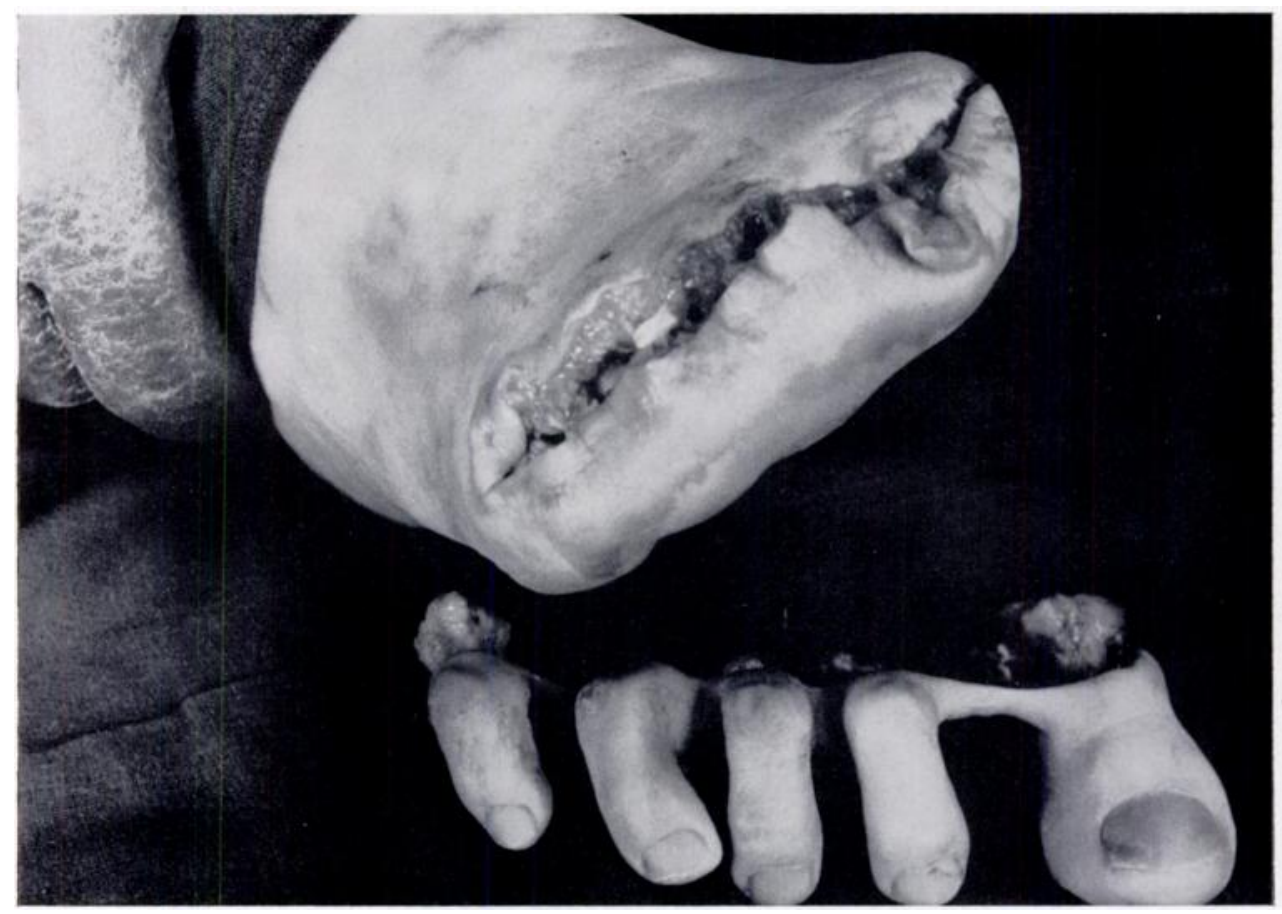

FIG. 4

Toes after disarticulation-joined by narrow bridges of skin from webs. 
the toes have been disarticulated, they are found to be joined together by a narrow bridge of skin from each web (Fig. 4). Any lateral or plantar prominence of the metatarsals is trimmed off and any evident rheumatoid cysts are removed. The wound is closed with interrupted sutures. The suture line comes to lie well dorsal to the pressure areas on the sole.

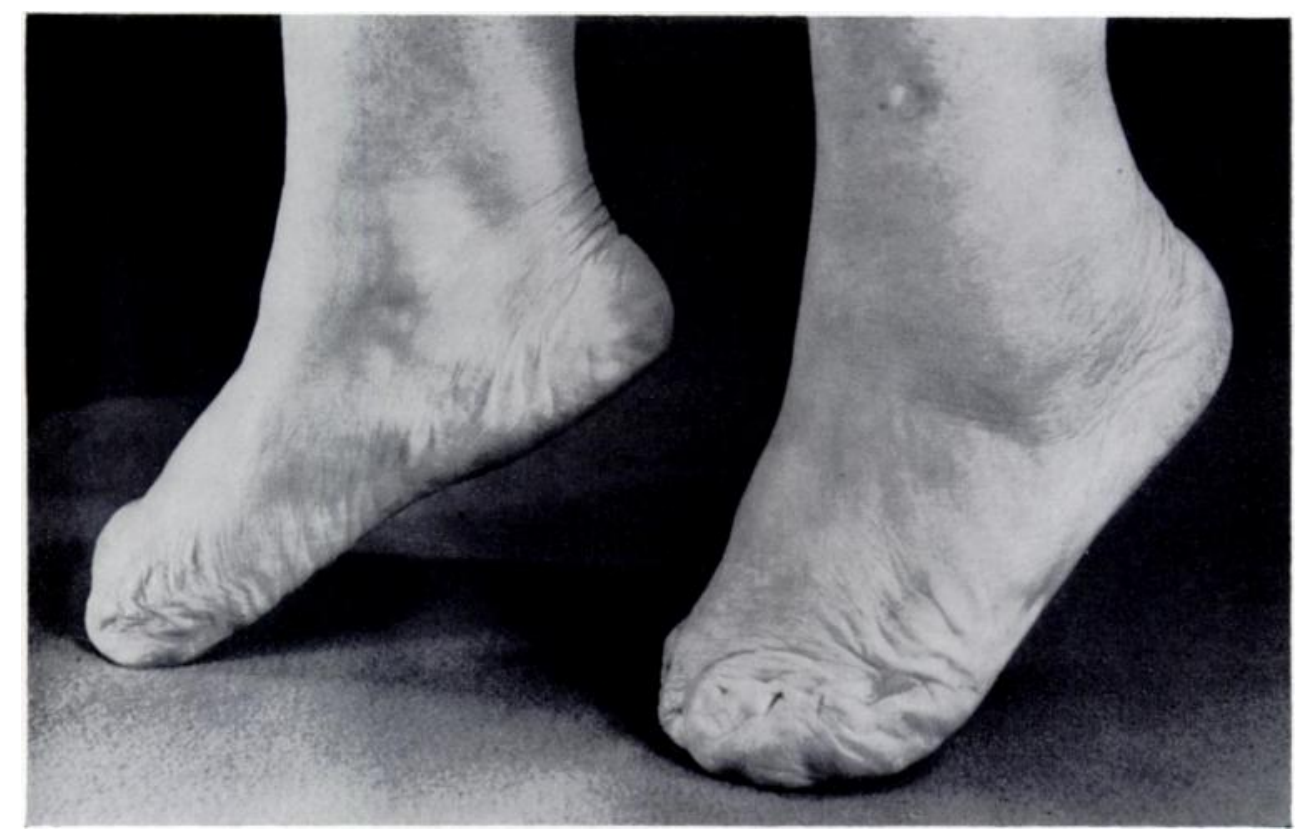

Fig. 5

Healed stumps showing suture line away from weight-bearing area

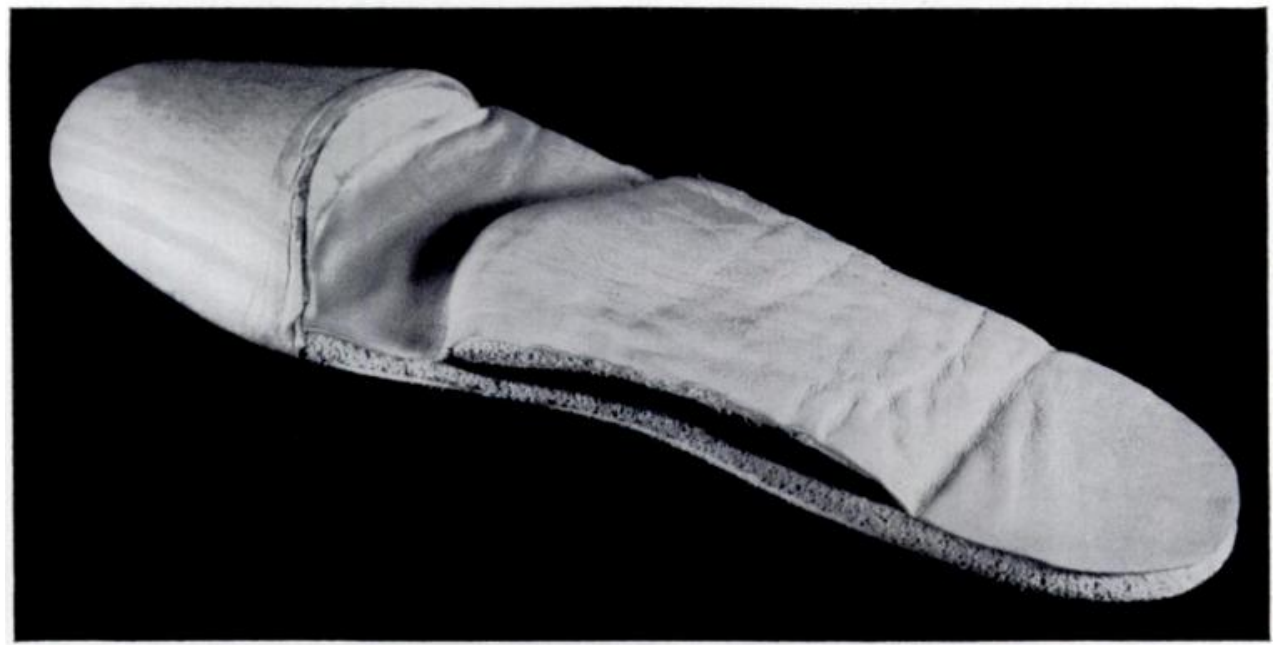

FIG. 6

Sponge rubber insole with metatarsal padding and toe block.

\section{POST-OPERATIVE MANAGEMENT}

The pressure dressing is retained until the sutures are removed on the tenth day. When the wound is healed a special insole is provided (Fig. 6). This insole is covered with sponge rubber and incorporates a combined metatarsal and cavus support, together with a cork 
toe block faced with sponge rubber. Either ordinary or surgical shoes are worn, according to the width of the forefoot. A few patients have preferred normal shoes without insoles. We have found it important to provide shoes of full length; short surgical shoes made to fit the tocless feet are not only uncomfortable and unsightly, but lead to instability. The length and natural flexibility of the normal shoe seems to compensate for the stabilising function of even grossly deformed toes, a factor easily forgotten when such toes are regarded as functionless. Catterall has used the Downie prosthesis and has found it very satisfactory.

\section{RESULTS}

Of the twenty-eight patients whom we have been able to trace, nineteen had both feet operated upon and so forty-seven toeless feet were available for review. The average length of follow-up was five and a half years. The cause of deformity and age at operation are given in Table I.

TABLE I

Analysis of Twenty-eight Patients Subjected to Amputation of All the Toes on One or Both Feet

\begin{tabular}{|c|c|c|c|c|c|c|c|c|}
\hline \multirow{2}{*}{ Etiology } & \multirow{2}{*}{ Number } & \multirow{2}{*}{ Unilateral } & \multirow{2}{*}{ Bilateral } & \multirow{2}{*}{$\begin{array}{c}\text { Average } \\
\text { age }\end{array}$} & \multirow{2}{*}{$\begin{array}{c}\text { Follow-up } \\
\text { (years) }\end{array}$} & \multicolumn{3}{|c|}{ Results } \\
\hline & & & & & & Excellent & Good & Fair \\
\hline Rheumatoid arthritis . & 12 & 2 & 10 & 51 & 8 & 6 & 4 & 2 \\
\hline Hallux valgus . & 8 & 4 & 4 & 52 & 5 & 8 & - & - \\
\hline Pes cavus (and neurological) & 7 & 2 & 5 & 41 & 7 & 6 & 1 & - \\
\hline Injury & 1 & 1 & - & $15 *$ & 2 & 1 & - & - \\
\hline All groups & 28 & 9 & 19 & 49 & $5 \cdot 6$ & $21(75 \%)$ & 5 & 2 \\
\hline
\end{tabular}

* This case not included in average age.

Before operation the patients were all severely handicapped. One patient suffering from severe rheumatoid arthritis was bedridden but subsequently got about again. Most patients were unable to wear ordinary shoes before operation.

All twenty-eight patients felt that they had been improved by operation. Those patients who had no significant discomfort in the feet, no stump tenderness and no tender callus under prominent metatarsal heads, and who felt that they had been greatly improved by the operation. were classed as having an excellent result. Patients who were well pleased with their feet but still had some tenderness of the stump or metatarsal heads were graded as having a good result. Those who had considerable discomfort under the metatarsal heads, but less than before amputation, or who complained of instability, were classed as having a fair result.

Of the twenty-eight patients, twenty-one had excellent, five good, and two fair results. The two described as fair were troubled particularly by instability and metatarsal head pressure from wearing short unpadded shoes. They were made much more comfortable with new full length shoes and insoles.

\section{DISCUSSION}

Amputation of painful dislocated toes removes both the cause of local pain and disability, and the downward thrust on the metatarsal heads which aggravates the metatarsalgia. It might be thought that excision of all the toes would produce an unstable and unsightly foot and that dropping of the forefoot with a consequent increase in metatarsalgia would occur after the operation, but this has not been our experience. 
The Hancock committee (1947), appointed to assess disability after injury, reported that "amputation of all the toes leaves the main part of the foot intact and does not therefore have such a serious effect on the power and balance as trans-metatarsal amputation," but went on to state that " it does, however, tend to destroy the arch of the foot by damaging the flexor muscles and thus renders necessary the use of a surgical boot, without which walking is difficult." Because of this the committee proposed that the disability arising from loss of all toes should be assessed at 20 per cent for one foot and 40 per cent for both. We have found, however, that the arch of the foot is usually well preserved (Fig. 7). Many of the patients examined are able to wear normal shoes with metatarsal pads and toe blocks (Fig. 8), and sometimes even these have been discarded.

On the other hand, the preservation of a fulllength shoe is a necessity. It seems that apparently functionless toes have some use in the maintenance of balance. The provision of normal length shoes with toe blocks compensates for the loss of the toes and makes it possible for the patient to walk normally.

We have not found that amputation produces

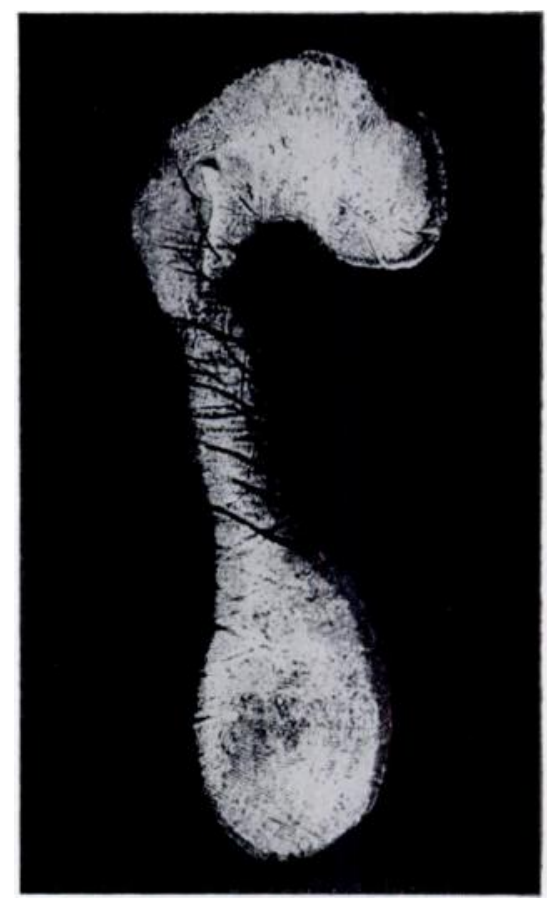

FIG. 7

Footprint showing preservation of arch. either dropping of the forefoot or any increased prominence of the metatarsal heads. Those patients without anterior flat foot before operation have not developed it and most of those with previous metatarsalgia improved after operation. It is of interest that the one amputation necessitated by injury produced "no disability whatsoever" in the words of the patient and

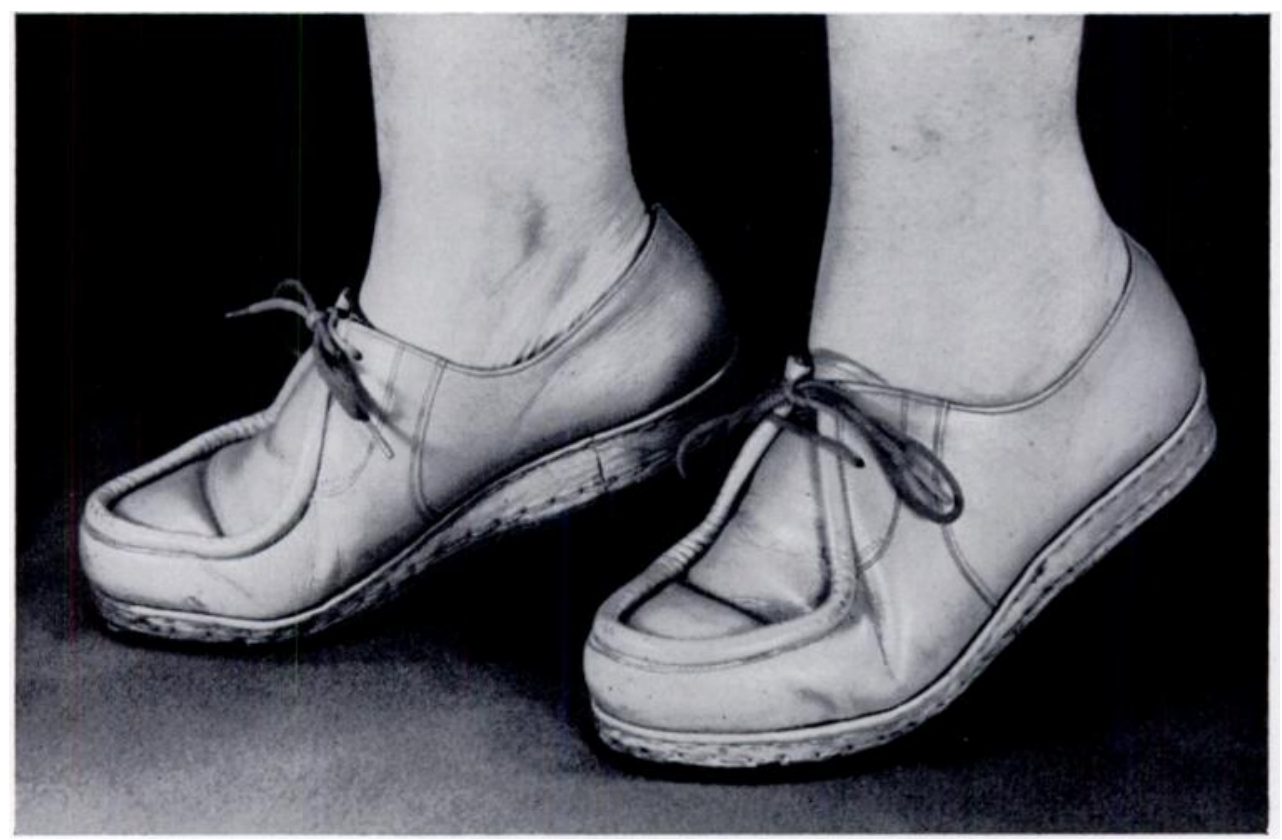

Fig. 8

Normal shoes worn after amputation.

VOL. 42 B, NO. 1, FEBRUARY 1960 


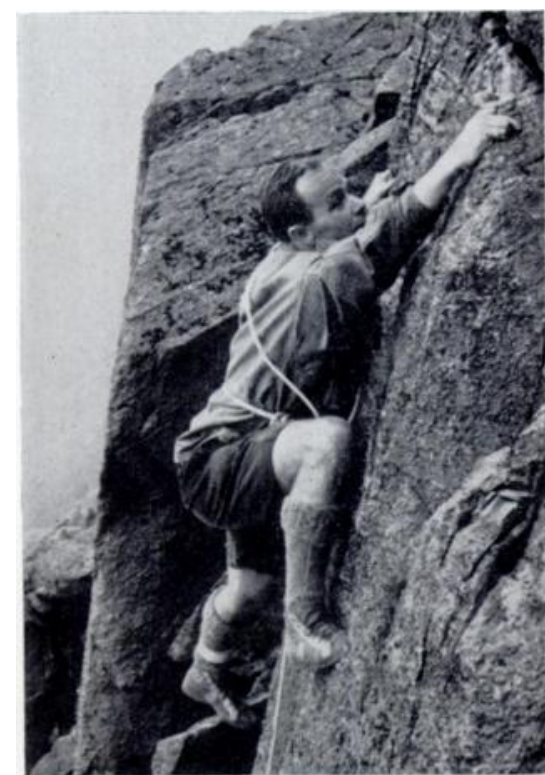

FIG. 9

This mountaineer was able to resume climbing after suffering loss of all the toes of both feet in consequence of frostbite. that examination revealed an otherwise normal foot without any callus under the metatarsal heads. We also know of an active mountaineer who, having lost all the toes from both feet by frostbite, continues mountain climbing (Fig. 9).

In our opinion amputation of all the toes is a valuable procedure and should be more widely employed in the treatment of fixed claw-toe deformity associated with multiple metatarso-phalangeal dislocations.

\section{SUMMARY}

1. The indications for amputation of all the toes for severe toe deformity in rheumatoid arthritis, hallux valgus and pes cavus are discussed.

2. The results of forty-seven amputations in twentyeight patients are analysed: 93 per cent were found to be very satisfied with the operation.

3. The technique of the operation and the subsequent management are described. The importance of retaining full-length shoes fitted with metatarsal insoles and toe blocks to preserve a good gait and balance is emphasised.

It is a pleasure to express our thanks to $\mathrm{Mr} \mathrm{K}$. I. Nissen for allowing us to review his cases which form most of this series and for his help in the preparation of this paper.

We also wish to thank Mr H. Jackson Burrows and Mr I. G. MacKenzie for their help and advice; and the consultant surgeons on the staff of the Royal National Orthopaedic Hospital for permitting us to see their patients.

We wish to express our gratitude to Mrs M. Glen Haig and Mr R. J. Whitley and their staff for their help with the follow-up and photographs.

\section{REFERENCES}

Catterall, R. C. F., and Oakley, W. G. (1957): The Management of Lesions of the Feet in Diabetics. In British Surgical Practice, Surgical Progress 1957, p. 15. London: Butterworth \& Co. (Publishers) Ltd.

Fowler, A. W. (1957): The Surgery of Fixed Claw Toes. Journal of Bone and Joint Surgery, 39-B, 585.

Fowler, A. W. (1959): A Method of Forefoot Reconstruction. Journal of Bone and Joint Surgery, 41-B, 507. HendRY, A. M. (1959): Personal communication.

Hoffmann, P. (1912): An Operation for Severe Grades of Contracted or Clawed Toes. American Journal of Orthopaedic Surgery, 9, 441.

interdepartmental Committee on the Assessment of Disablement Due to Specified Injuries (1947): Report, p. 10. (Command 7076), London: H.M. Stationery Office.

Nissen, K. I. (1953): The Place of Amputation of All Toes. Journal of Bone and Joint Surgery, 35-B, 488.

Nissen, K. I. (1957): Amputation of All Five Toes. In Operative Surgery, Vol. 5, p. 301. Edited by C. Rob and R. Smith. London: Butterworth \& Co. (Publishers) Ltd.

PRIDIE, K. H. (1959): Personal communication.

SAYLE-Creer, W. (1959): Personal communication.

$$
\mathrm{F}-\mathbf{1}_{(4)}
$$

